\title{
The race for telecoms infrastructure investment with bypass: Can access regulation achieve the first best?*
}

\author{
João Vareda ${ }^{\dagger}$ \\ FEUNL ${ }^{\ddagger}$ \\ Autoridade da Concorrência \\ Steffen Hoernig
FEUNL
CEPR
}

November, 2007

\begin{abstract}
We analyze the impact of mandatory access on the infrastructure investments of two competing communications networks, and show that for low (high) access charges firms wait (preempt each other). Contrary to previous results, under preemption a higher access charge can delay first investment. While first-best investment cannot be achieved with a fixed access tariff, simple instruments such as banning access in the future, or granting access holidays right after investment, can improve efficiency. The former forces investment when it would happen too late, while the latter allows for lower access charges in order to delay the second investment when it would happen too early.

JEL classification: D92, L43, L51, L96

Keywords: Access pricing, Investments, Preemption, Access ban, Access holidays
\end{abstract}

${ }^{*}$ We are thankful for financial support from POCI 2010/FCT and FSE and project POCTI/ECO/44146/2002 of FCT and FEDER. We would also like to thank Iñigo Herguera, Tommaso Valletti, the participants at the JEI Conference (Barcelona, September 2006), at the ASSET Conference (Lisbon, November 2006), at the IIOC (Savannah, April 2007), at the PEJ Meeting (Ponta Delgada, June 2007), at the ESEM Conference (Budapest, August 2007), at the ITS Regional Conference (Istanbul, September 2007), and at the EARIE Conference (Valencia, September 2007), and Mark Armstrong and two anonymous referees. The opinions expressed in this article reflect only the authors' views and in no way bind the institutions to which they are affiliated.

${ }^{\dagger}$ Corresponding author.

${ }^{\ddagger}$ School of Economics, Universidade Nova de Lisboa, Campus de Campolide, 1099-032 Lisboa, Portugal. E-mails: jvareda@fe.unl.pt, shoernig@fe.unl.pt 


\section{Introduction}

Access regulation and investment. Over the last decades, one of the main goals of economic regulation has been to increase competition in markets that have traditionally been less competitive. At the same time, technological progress has come to be seen as a fundamental driving force of economic performance. In telecommunications, plans for the introduction of advanced networks generate such high expectations about new or improved services, and acceleration of economic growth and competitiveness, that not discouraging the necessary investments should be among regulators' primary concerns.

Regulators thus need to manage a trade-off between the two objectives of static and dynamic efficiency, which are often conflicting. While regulation for static efficiency aims to reduce market power based on existing infrastructure, it also reduces the rents on future investment. Hence, regulators face the difficult task of determining how to encourage operators to invest optimally without lessening competitive intensity.

In recent years, telecommunications markets have seen high rates of technological progress. Several substitutes for existing copper networks have been developed, all allowing the creation of new broadband services: bi-directional cable networks, fixed wireless local loops (FWA or WiMax), and upgraded cellular mobile networks. Most of these alternatives continue to involve large sunk costs and economies of scale, which makes it difficult for many firms to invest immediately.

One of the main instruments used by regulators to reduce the temporary monopoly power of existing networks is to force them to give access. The idea is that rivals can first compete as service-based competitors, before they build their own networks and turn into facility-based competitors. This regulatory instrument has gained an important role since it started to be promoted more strongly in the United States after 1996 with the Telecommunications Act and in the European Union after the 1998 liberalization, especially in the form of the "unbundling of the local loop". According to the European Commission, service-based competition is a pre-requisite for future facilitybased competition. The achievement of the latter is desirable since it creates a high scope for product differentiation and innovation.

The relation between access regulation and investment can be a highly controversial issue, as recent headlines show. For instance, in 2006 there was a dispute between the European Commission on the one hand, and the German government and Deutsche Telekom on the other, about mandating access to the VDSL network that Deutsche Telekom plans to build in fifty German 
cities. Deutsche Telekom claimed the right to an access holiday to this future network, and the government offered its support. The European Commission counter-argued that existing ex-ante regulation had to be extended also to this network, since the lack of competition in the German market could lead to the re-emergence of monopoly. Similarly, telecommunications companies that invest in "new generation networks", which involve fibre as close to the home as possible and transmission of all data using the IP protocol, claim that they should be subject to fewer access obligations.

Model and results. In our model there are two ex-ante symmetric firms that intend to operate in a market, and new infrastructure must be built to allow these firms to offer new services. Investment costs decline over time because of technological progress, and the construction of a second network, bypassing the first one, will be viable and socially desirable at some point in time, since it allows firms to offer more differentiated services. The second firm (the "follower") can access its rival's (the "leader's") infrastructure at a regulated two-part access tariff before it builds its own network. The follower's choice of investment will depend on the conditions of access.

Firms generally have two incentives for the first investment, a standalone incentive and a preemption incentive. The stand-alone incentive stems directly from the increase in profits after investment. In the absence of strategic effects, firms would choose investment timing by trading off earlier gains in profit against lower investment costs later on. The second incentive to invest is related to the advantage of being the first to invest. In fact, if a firm does not invest, a rival firm may do so and become the common provider. If being a leader is more profitable than being a follower, each firm has incentives to preempt the other firm's investment. If, on the contrary, being a follower is more profitable, both firms only have the stand-alone incentive to invest, and there is no race to become the leader.

We first determine the equilibrium in terms of investment patterns. Indeed, two types of equilibria are possible, preemption if there is a first-mover advantage caused by a high access charge, and waiting if there is a secondmover advantage due to a low access charge. In the preemption equilibrium the leader invests at the preemption date, while in the waiting equilibrium it invests at its stand-alone investment date. The follower always invests at its stand-alone investment date.

Both the leader's investment in a waiting equilibrium, and the follower's investment in both types of equilibria, occur earlier with a higher access charge. This happens because the stand-alone incentives to invest increase with the access charge. Yet, contrary to Hori and Mizuno (2006), the effect 
of the access charge on the leader's investment decision in a preemption equilibrium is ambiguous. Besides strengthening the stand-alone incentive, a higher access charge makes being the follower less attractive and therefore strengthens the preemption motive. On the other hand, since the follower invests earlier, the duration of service-based competition will be shorter, which lowers the returns on the first investment. This second effect may be stronger than the first two, and investment is delayed.

We then consider whether first-best investment can be achieved by a regulator who controls the conditions of access. Indeed, socially optimal investment by both leader and follower cannot be achieved by just using a fixed access tariff. This is intuitive since one regulatory instrument normally cannot achieve two independent goals. In principle, access charges that change over time, as in Bourreau and Dogan (2006) or Vareda and Hoernig (2007), can be used to transmit correct incentives. The downside of this idea is that in practice it may be rather hard or outright impossible for a regulator to commit to a path of access charges even in the medium run. ${ }^{1}$ Therefore we consider the simplest possible change from a fixed access price: not allowing access after some point in time, which is essentially equivalent to setting an infinite access price, or not forcing the leader to give access during some period of time. The regulator then only must commit to the date when the access price is changed.

As with generic time-varying access charges, the point of departure is the rents that the leader will earn until the follower's investment. In particular, access holidays guarantee a period of monopoly profits, which in turn makes it possible for the regulator to charge lower access price later on while still giving correct incentives for the leader's investment.

If the follower's private incentives for investment are low compared to its effect on total welfare, the access price that makes the leader invest at the socially optimal date is too low, and the follower invests too late. Banning access right after the socially optimal date for a second investment makes the follower invest optimally, and the first-best can be achieved. This one instance of an increasing path of access prices, as advocated by Cave and Vogelsang (2003).

On the other hand, if the follower's business stealing incentives are very strong, it might invest too early rather than too late. In this case the regulator would like to delay its investment through a lower access price, which would make the leader invest too late. As mentioned above, a period of "ac-

\footnotetext{
${ }^{1}$ For instance, "glide-paths" such as those used by European telecommunications regulators for lowering termination charges typically do not have a duration of more than two years.
} 
cess holidays", where the leader does not have access obligations for some time after its investment, protects the incentives of the leader. These access holidays will then be followed by a lower access charge until the follower's investment, that is, the access holidays in this case mainly function as a prelude to these lower access charges. Contrary to the previous case, the first-best cannot be achieved because there will be losses of static welfare and there may exist a conflict between the necessary length of the access holiday and the necessity to avoid early bypass.

Finally, we consider two extensions to our model. First we consider the case where duplication is either not socially or privately desirable, and show that our previous conclusions continue to hold. As a second extension, we briefly analyze ex-ante asymmetric firms by assuming that one of the firms only needs to upgrade an existing network to supply new services. Sure enough, this firm will invest first in equilibrium. The main qualitative difference to the ex-ante symmetric case is that socially optimal investment timing can be achieved in a waiting equilibrium when the asymmetry is large enough. Still, if the asymmetry is small enough then the regulator will need to encourage preemption, just as in the symmetric case.

Related literature. The academic literature on regulation has only recently started to address the issue of access pricing and investment. For example, Valletti (2003) claims that this type of problems had not been studied sufficiently. However, he gives some clues towards understanding it by relating the issue with questions common to the literature on $R \& D$. Guthrie (2006) provides a survey on the recent literature about the relationship between infrastructure investment and the different regulatory regimes, concluding that much has still to be done in this field.

Bourreau and Dogan (2005) consider a model of infrastructure investment in a telecommunications market with access regulation. One of the firms already owns an infrastructure, and thus only the other firm must decide if it wants to enter as a service-based or facility-based competitor. Therefore, the regulator simply has the problem of setting an access price such that the entrant duplicates at the socially optimal investment date. Bourreau and Dogan (2006) consider a similar model but allow for the use of a timevariant access price.

Gans (2001) considers a context similar to Katz and Shapiro (1987). Two firms compete to invest in a new technology, and there will be only one investment. In this case the regulator can induce the leader to invest at the socially optimal date, for which he uses the access charge.

Woroch (2004) provides a formal model of a technology race among network owners and service providers and studies the equilibrium broadband 
deployment pattern, allowing for duplication. He finds the equilibrium in terms of investment dates and analyzes the impact of mandatory access on the investment pattern, as we do in our paper. However he does not consider the presence of a regulator who maximizes social welfare as we do, and therefore does not consider the choice of a socially optimal access tariff

Hori and Mizuno (2006) consider a model with two investments, assuming a stochastically and indefinitely growing demand instead of technical progress. In their model flow payoffs are always symmetric, contrary to ours where the leader may have higher payoffs even before taking into account access revenue. They obtain an equilibrium in a preemption game, since they explicitly rule out a waiting equilibrium, and conclude that the incentive for preemption can be enhanced by an increase in the access tariff. While we believe that our assumption of investment costs that are falling to some level is more realistic than that of demand forever growing at constant rate as in Hori and Mizuno, the main difference between our paper and theirs is that we consider the effect of access prices on the type of equilibrium and investigate alternative regulatory instruments that supplement access prices in the quest for achieving the first best.

A second strand of literature that is relevant in this context it that about races for technology adoption. The underlying assumption in all models is that investment cost declines over time, for example due to technical progress. The game is then one of timing of investment, i.e. firms' only choices are their respective investment dates.

In Fudenberg and Tirole (1985) two or more firms adopt a new technology. Since they assume that it is better to be the first to adopt, the equilibrium outcome in the duopoly case is either preemption or joint adoption. Rent equalization occurs, i.e., the race for preemption equalizes discounted payoffs of leaders and followers at the equilibrium investment date.

Katz and Shapiro (1987) consider a similar model where only one firm adopts and then offers a licence to the other firm. They show that preemption or waiting may occur in equilibrium. The waiting equilibrium arises due to a second-mover advantage, and the follower has a higher firm value.

Riordan (1992) considers the effects of regulation of entry and retail prices when both firms can adopt. Since, by assumption, the follower cannot access the first network, access pricing is not an issue. Still, in spirit this paper is closest to ours in that it analyses how regulation affects investment dates.

Hoppe and Lehmann-Grube (2005) show how equilibria can be analyzed if the leader's profit as a function of its investment date has multiple local maxima or is discontinuous. 
The remainder of the paper is organized as follows. We describe the model in Section 2. In Sections 3 and 4 we obtain the equilibrium investment timing for both firms and analyze the impact of the access tariff. In Sections 5 and 6 we find the socially optimal investment timing and solve the regulator's problem. In Section 7 we consider some extensions, and in Section 8 we conclude.

\section{The Model}

We introduce a model where two firms compete for the construction of network infrastructure that allows them to offer new services. After one firm has built the infrastructure, it must give access to its rival at a regulated price. The regulator sets a two-part access tariff which consists of a usage charge $a$ and an access charge $P \geq 0$. These are set $e x$ ante, i.e., when firms invest the access rules are already defined and known to both.

Here we only analyze the aspects concerning dynamic efficiency, assuming that the regulator has full information about the firms' technology and payoffs. Therefore, we assume that the usage charge $a$ is used to maximize static efficiency, as in Gans (2001). Hence, we can think of the access tariff as just an access charge, and concentrate on its optimal choice.

The two firms that can build the infrastructure know that if a firm "wins" in the provision of the infrastructure it becomes the common provider, and if it "loses" it either pays for access or builds a bypass network. This setup can create a first-mover advantage which stimulates a preemption process. However, there may also be a second-mover advantage which will lead to a game where preemption does not occur. This second case arises since the follower benefits from the first investment through access and then invests later when technological progress has brought down costs.

Depending on the pattern of infrastructure investment, there are different market structures over time. When only one firm has invested, it must give access to the rival, and there is service-based competition. When both firms have invested, we have facility-based competition. Each firm's profit at a given point in time only depends on the investment pattern up to this date.

\section{Firms' payoffs}

We assume that firms are ex-ante symmetric, and that time is continuous. Hence, at the beginning of the game, when neither of the firms has invested, each earns flow profits of $\pi_{0}$. When one firm has invested and gives access, it obtains the leader's flow profit $\pi_{1 L}+P$. If the follower asks for access it receives $\pi_{1 F}-P$ per period, and otherwise zero. Thus, after the 
leader's investment, the follower obtains $\tilde{\pi}_{1 F}(P)=\max \left\{\pi_{1 F}-P, 0\right\}$, while the leader's profits are:

$$
\tilde{\pi}_{1 L}(P)=\left\{\begin{array}{cc}
\pi_{1 L}+P & \text { if } P \leq \pi_{1 F} \\
\pi_{1 M} & \text { if } P>\pi_{1 F}
\end{array},\right.
$$

where $\pi_{1 M}$ is the monopoly profit. We assume:

$$
\begin{aligned}
\pi_{1 F} & \geq 0 \\
\pi_{1 M} & \geq \pi_{1 L}+\pi_{1 F} .
\end{aligned}
$$

Since profits do not depend on $P$ if $P>\pi_{1 F}$, the relevant range for $P$ is the interval $\left[0, \pi_{1 F}\right]$, which is not empty by assumption $(2)$. It follows that $\tilde{\pi}_{1 L}(P) \leq \pi_{1 M}$.

When both firms have invested, the leader's flow profit is $\pi_{2 L}$ and the follower's is $\pi_{2 F}$, with:

$$
\pi_{2 L} \geq \pi_{2 F}
$$

\section{Investment cost}

Each infrastructure is built at a single moment, and the investment cost is decreasing over time due to technological progress. We also assume that firms hold on to the technology indefinitely once they have invested, and that the infrastructure does not deteriorate over time. This allows us to avoid the issue of re-investment. Current investment cost at time $t$ is $C(t)$, which we assume to be a positive, decreasing and convex, and twice continuously differentiable function: ${ }^{2}$

$$
C(t)>0, C^{\prime}(t)<0, C^{\prime \prime}(t)>0 \quad \forall t \in \mathbb{R} .
$$

This implies that $\lim _{t \rightarrow \infty} C(t)=\underline{C} \geq 0$ and $\lim _{t \rightarrow \infty} C^{\prime}(t)=0$. We assume that both the leader and the follower would want to invest in finite time. The follower's investment is motivated by the possibility of a higher differentiation of its services from its rival's. There are decreasing returns to investment, in the sense that the increase in the leader's flow profits exceeds the follower's:

$$
\pi_{1 L}-\pi_{0}>\pi_{2 F}-\pi_{1 F}>\delta \underline{C} .
$$

Later, when we analyze a context where a bypass investment may not be desirable, we allow $\underline{C}$ to be higher. Let the discount rate be $\delta>0$. Investment cost discounted to time zero is $A(t)=C(t) e^{-\delta t}$, which is decreasing in $t$ and converges to zero.

\footnotetext{
${ }^{2}$ We extend the definition of investment cost to dates before zero in order to simplify the exposition below.
} 
To rule out immediate investment, we assume that investment at time zero leads to losses:

$$
\delta C(0)>\max \left\{\pi_{1 M}, \pi_{2 L}\right\} .
$$

Since $A^{\prime}(0)=C^{\prime}(0)-\delta C(0)$ and $A(0)=C(0)$, we have $-A^{\prime}(0)>\delta A(0)$.

\section{Firms' strategies}

Each firm plays a Markov strategy that is a function of time $t$, the access tariff $P$, and whether its rival has already invested or not. For each firm, the only decision to be made is when to make a unique investment.

We assume that simultaneous investment is not possible. For various technical implementations of this assumption see Hoppe and Lehmann-Grube (2005).

\section{Investment Timing}

Let us start to examine what happens when one of the firms, say firm $i$, has invested at some time $t_{i}$. In this case we need to solve the follower's investment problem in the continuation game.

Given the leader's investment at $t_{i}$ and the access tariff, the discounted payoff of the follower investing at $t_{j} \geq t_{i}$ is:

$$
\begin{aligned}
\tilde{F}\left(t_{i}, t_{j}, P\right) & =\int_{0}^{t_{i}} \pi_{0} e^{-\delta t} d t+\int_{t_{i}}^{t_{j}} \tilde{\pi}_{1 F}(P) e^{-\delta t} d t+\int_{t_{j}}^{\infty} \pi_{2 F} e^{-\delta t} d t-A\left(t_{j}\right) \\
& =\frac{1-e^{-\delta t_{i}}}{\delta} \pi_{0}+\frac{e^{-\delta t_{i}}-e^{-\delta t_{j}}}{\delta} \tilde{\pi}_{1 F}(P)+\frac{e^{-\delta t_{j}}}{\delta} \pi_{2 F}-A\left(t_{j}\right) .
\end{aligned}
$$

Before $t_{i}$ no firm has invested, and profits are $\pi_{0}$. Between $t_{i}$ and $t_{j}$, there is a period of service-based competition. After duplication, both firms offer their services through their own infrastructure, and we end up in facility-based competition.

Now we can determine the follower's optimal investment date. First define, for all $t \in \mathbb{R}$,

$$
Z(t)=-A^{\prime}(t) e^{\delta t}=\delta C(t)-C^{\prime}(t) .
$$

This is a continuously differentiable and strictly decreasing function, with $\lim _{t \rightarrow-\infty} Z(t)=+\infty$ and $\lim _{t \rightarrow+\infty} Z(t)=\delta \underline{C}$.

The only incentive for investment that influences the follower's decision is the stand-alone incentive. It weighs the benefit of higher payoffs of investing 
today against the cost savings of delaying investment. There is no preemption motive since its rival has already invested.

Proposition 1 Given the access charge $P$ and the leader's investment date $t_{i} \geq 0$, the follower invests at:

$$
T_{F}\left(t_{i}, P\right)=\max \left\{T_{f}(P), t_{i}\right\}
$$

where $T_{f}(P)=Z^{-1}\left(\pi_{2 F}-\tilde{\pi}_{1 F}(P)\right)>0$.

Proof. The follower solves

$$
\max _{t_{j} \geq t_{i}}\left\{\frac{\pi_{2 F}-\tilde{\pi}_{1 F}(P)}{\delta} e^{-\delta t_{j}}-A\left(t_{j}\right)\right\}
$$

with first-order condition:

$$
\pi_{2 F}-\tilde{\pi}_{1 F}(P)=-A^{\prime}\left(t_{j}\right) e^{\delta t_{j}}=Z\left(t_{j}\right) .
$$

By assumption (6) the left-hand side is larger than $\delta \underline{C}$, and by assumptions (4) and (7) we have:

$$
\pi_{2 F}-\tilde{\pi}_{1 F}(P) \leq \pi_{2 L}<-A^{\prime}(0)=Z(0) .
$$

Thus $T_{f}(P)=Z^{-1}\left(\pi_{2 F}-\tilde{\pi}_{1 F}(P)\right)$ is well-defined, unique and positive. The second derivative of profits is ${ }^{3}$

$$
\begin{aligned}
\frac{\partial^{2} \tilde{F}\left(t_{i}, T_{f}, P\right)}{\partial t_{j}^{2}} & =\delta\left(\pi_{2}-\tilde{\pi}_{1 F}(P)\right) e^{-\delta T_{f}}-A^{\prime \prime}\left(T_{f}\right) \\
& =Z^{\prime}\left(T_{f}\right) e^{-\delta T_{f}}<0
\end{aligned}
$$

hence we have a maximum. If $T_{f}(P) \leq t_{i}$ then the optimal choice is to invest at $T_{F}=t_{i}$, otherwise it is at $T_{F}=T_{f}(P)>t_{i}$.

Denote the follower's profit at its optimal investment date as $F\left(t_{i}, P\right)=$ $\tilde{F}\left(t_{i}, T_{F}\left(t_{i}, P\right), P\right)$. Note that $T_{f}(P), T_{F}\left(t_{i}, P\right)$ and $F\left(t_{i}, P\right)$ are continuous functions, and that $F\left(t_{i}, P\right)$ is positive for all $t_{i} \geq 0$ and $P \in\left[0, \pi_{1 F}\right]$. Note also that for all $t_{i} \in\left[0, T_{f}(P)\right], F\left(t_{i}, P\right)$ is increasing in $t_{i}$ if $\pi_{0}>$ $\tilde{\pi}_{1 F}(P)$, or $P>\pi_{1 F}-\pi_{0}$, and decreasing otherwise. Since in this case the follower's investment date does not depend on $t_{i}$, if the follower's flow profit

\footnotetext{
${ }^{3}$ Below we omit second-order conditions since they hold and are similar to the present one.
} 
decreases after the leader's investment its discounted payoff increases if the leader invests later.

Now that we have determined the follower's choice in the continuation game, we can define the discounted payoff of a leader investing at $t_{i}$ as $L\left(t_{i}, P\right)=\tilde{L}\left(t_{i}, T_{F}\left(t_{i}, P\right), P\right)$, where

$$
\tilde{L}\left(t_{i}, t_{j}, P\right)=\frac{1-e^{-\delta t_{i}}}{\delta} \pi_{0}+\frac{e^{-\delta t_{i}}-e^{-\delta t_{j}}}{\delta} \tilde{\pi}_{1 L}(P)+\frac{e^{-\delta t_{j}}}{\delta} \pi_{2 L}-A\left(t_{i}\right) .
$$

We first determine the leader's stand-alone investment date $T_{S}(P)$. Given that one firm must be the leader, the first investment will not occur after this date. Preemption before this date may occur, though.

Proposition 2 Given the access charge $P$, the leader's stand-alone investment date $T_{S}(P)$ is at either $T_{s}(P)<T_{f}(P)$ or $T_{s^{\prime}}>T_{f}(P)$, with

$$
T_{s}(P)=Z^{-1}\left(\tilde{\pi}_{1 L}(P)-\pi_{0}\right), \quad T_{s^{\prime}}=Z^{-1}\left(\pi_{2 L}-\pi_{0}\right) .
$$

If $P \leq \pi_{1 F}-\pi_{0}+\pi_{2 L}-\pi_{2 F}$ then it is at $T_{s}(P)$, otherwise it can be one or the other.

\section{Proof. See Appendix A.}

There may exist two local maxima in the leader's discounted payoff, as has already been pointed out in Fudenberg and Tirole (1985) in a similar context. The first one, $T_{s}(P)$, and which always exists, occurs before the follower's investment date $T_{f}(P)$, and thus leads to a period of service-based competition. The second local maximum at $T_{s^{\prime}}$ only arises when $P$ is high, and leads to immediate bypass by the follower. In this case, there is no period of service-based competition. In both cases $L\left(T_{S}(P), P\right)$ is positive, but when its second local maximum exists we cannot determine the location of its global maximum with our generic specification of investment cost. ${ }^{4}$

In equilibrium the leader may not invest at $T_{S}(P)$, since for high values of $P$ the threat of preemption will induce investment at an earlier date. Indeed, whenever $L\left(t_{i}, P\right)>F\left(t_{i}, P\right)$ there is a first-mover advantage: The discounted payoffs of becoming a leader are strictly higher than the payoff

\footnotetext{
${ }^{4}$ Fudenberg and Tirole (1985) show that any one of the two local maxima can be the global maximum. They argue that $L\left(T_{s}\right)>L\left(T_{s^{\prime}}\right)$ is typical of new markets, where the profit after the investment in the infrastructure increases strongly. The opposite case, $L\left(T_{s}\right)<L\left(T_{s^{\prime}}\right)$, arises when the first investment simply transfers profit from the leader to the follower. The former fits better to our model, especially with ex-ante symmetry
} 
of becoming a follower. In this case firms will compete to be leaders, each trying to invest slightly earlier that its rival. In equilibrium, one firm invests at the preemption date $T_{p}(P)$, which is the earliest date where firms are indifferent between being a leader or a follower. The following Proposition shows that the preemption date is well-defined:

Proposition 3 Given the access charge $P$, there is a unique date $T_{p}(P) \in$ $\left(0, T_{f}(P)\right]$ such that for all $t_{i} \in\left[0, T_{f}(P)\right)$ we have $L\left(t_{i}, P\right) \lesseqgtr F\left(t_{i}, P\right)$ if $t_{i} \lesseqgtr T_{p}(P)$.

\section{Proof. See Appendix B.}

Now we need to establish whether or not preemption will arise. The decisive factor is which of the two dates occurs earlier, the preemption or the stand-alone investment date. The following result is similar to Riordan (1992) and Hoppe and Lehmann-Grube (2005).

Proposition 4 For all $P \in\left[0, \pi_{1 F}\right]$, in subgame-perfect equilibrium the follower invests at $\widetilde{T}_{F}(P)=T_{f}(P)$, and the leader's investment $\widetilde{T}_{L}(P)<$ $\widetilde{T}_{F}(P)$ falls into two cases:

i) Preemption: If $T_{p}(P)<T_{s}(P)$, the leader invests at $\widetilde{T}_{L}(P)=T_{p}(P)$.

ii) Waiting: If $T_{p}(P) \geq T_{s}(P)$ the leader invests at $\widetilde{T}_{L}(P)=T_{s}(P)$.

This outcome is unique up to relabeling of firms.

Proof. Similar to the proof of Theorem 1 in Hoppe and Lehmann-Grube (2005). Note that in our model $L\left(t_{i}, P\right)-F\left(t_{i}, P\right)=e^{-\delta t_{i}} \frac{\pi_{2 L}-\pi_{2 F}}{\delta} \geq 0$ for all $t_{i} \geq T_{f}(P)$, thus we do not need to restrict $F$ to be non-increasing to obtain a unique outcome. Joint adoption equilibria, where both firms adopt at the same date $t_{i}>T_{f}(P)$, are ruled out by assumption.

Given the generic functional forms that we use and the implicit definition of $T_{p}$, there is no explicit parametric condition for the thresholds which determine the transitions between both equilibria.

We now plot the leader's and follower's payoffs as functions of the leader's investment date in order to explain the intuition of this result. We have two cases, depending on whether the follower's payoff is increasing (Figures 1 and 2 ) or decreasing (Figures 3 and 4$)$ until $T_{f}(P)$.

Remember that the follower's payoff $F\left(t_{i}, P\right)$ is (weakly) increasing in $t_{i}<T_{f}(P)$ if $P \geq \pi_{1 F}-\pi_{0}$. In this case we have

$$
L\left(T_{s}(P)\right)>L\left(T_{f}(P)\right) \geq F\left(T_{f}(P)\right) \geq F\left(T_{s}(P)\right),
$$


and there is a first-mover advantage. The equilibrium outcome is preemption at $T_{p}(P)$ because any attempt to wait with investment until some later date will be met with slightly earlier investment.

There are two sub-cases, depending on the leader's global maximum. In Figure 1 there is only one local maximum in the leader's payoff function, i.e. $P \leq \pi_{1 F}-\pi_{0}+\pi_{2 L}-\pi_{2 F}$, while in Figure 2 we have $P>\pi_{1 F}-\pi_{0}+\pi_{2 L}-\pi_{2 F}$ and a second local maximum. If one allow for simultaneous investment, then if the second maximum is high enough joint adoption equilibria just before $T_{s^{\prime}}$ may arise, see Fudenberg and Tirole (1985).

On the other hand, $F\left(t_{i}, P\right)$ is decreasing in $t_{i}<T_{f}(P)$ if $P<\pi_{1 F}-\pi_{0}$. The leader's payoff has only one local maximum, but now the outcome may be waiting or preemption. If $L\left(T_{s}(P)\right)>F\left(T_{s}(P)\right)$, as in Figure 3, then again there is a first-mover advantage and the outcome is preemption. On the other hand, if $L\left(T_{s}(P)\right)<F\left(T_{s}(P)\right)$, as in Figure 4, then there is a second-mover advantage, and we have a waiting equilibrium.

While being a known result in technology adoption games, the possibility of a waiting equilibrium is a novelty for models of access regulation. In fact, the existing literature generally obtains a simple preemption equilibrium, or rules waiting out by assumption (Hori and Mizuno, 2006). ${ }^{5}$

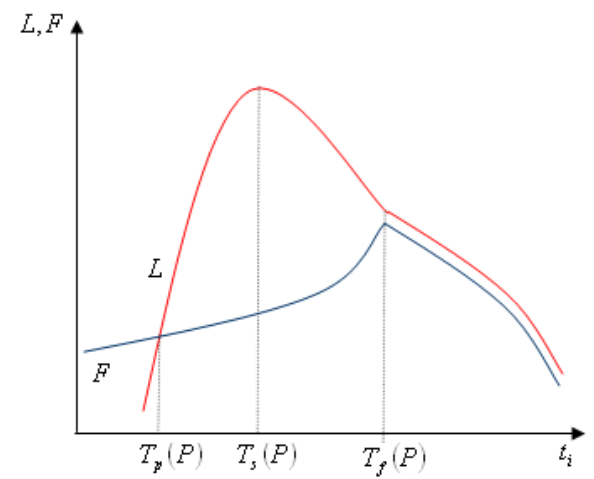

Figure 1

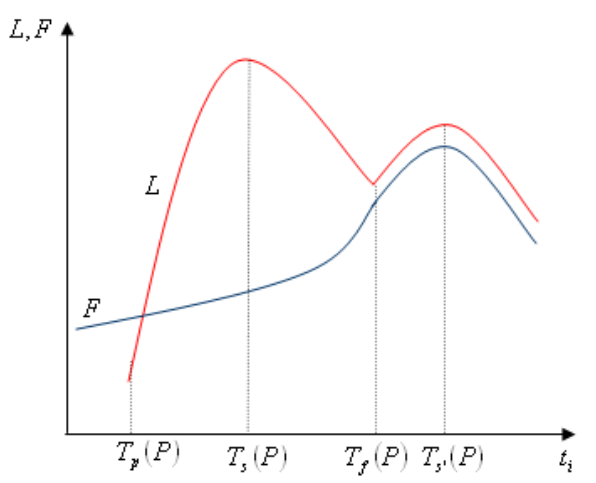

Figure 2

\footnotetext{
${ }^{5}$ Guthrie (2006) considers the possibility of a waiting equilibrium, but in the context of asymmetric firms. This will be discussed in the extensions of Section 7 .
} 


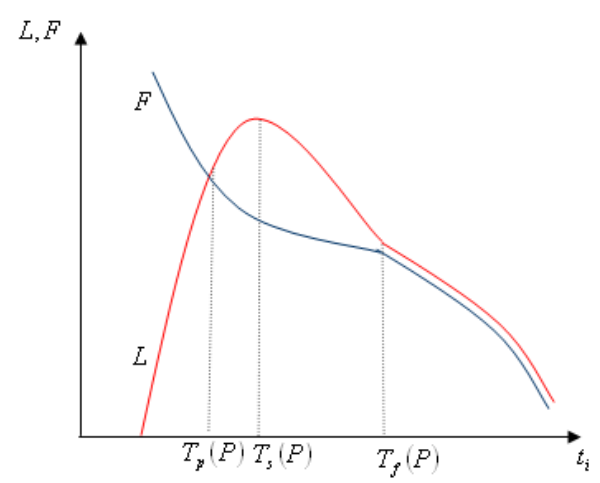

Figure 3

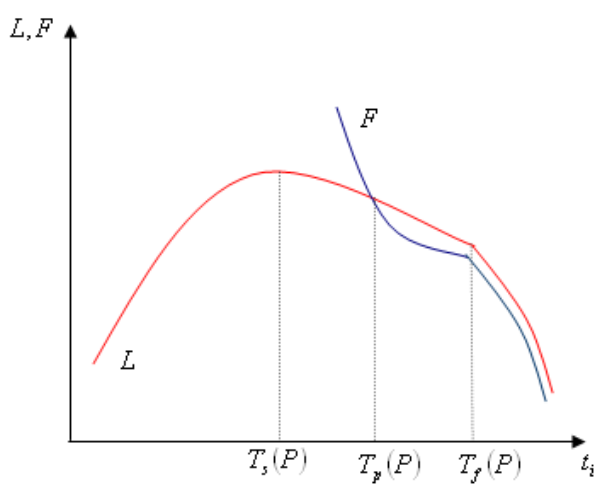

Figure 4

\section{Effects of the Access Tariff}

We can now determine the effect of the access tariff on the leader's and follower's investment dates.

Proposition 5 If the access charge $P \in\left[0, \pi_{1 F}\right]$ increases, the follower invests earlier.

Proof. From Proposition 1, $\frac{d T_{f}}{d P}=\left(Z^{-1}\right)^{\prime}\left(\pi_{2 F}-\pi_{1 F}+P\right)<0$.

With a higher access tariff, the follower makes fewer profits prior to its investment and, as a result, it invests earlier. Since $P=\pi_{1 F}$ leads to the same outcome as no access at all, mandatory access at $P<\pi_{1 F}$ always delays the follower's investment as compared to the situation without access.

With respect to the leader's decision, we need to analyze what happens when it waits or preempts.

Proposition 6 In a waiting equilibrium, a higher access charge $P \in\left[0, \pi_{1 F}\right]$ makes the leader invest earlier. In the preemption equilibrium, with a higher access charge $P \in\left[0, \pi_{1 F}\right]$ the leader invests earlier (later) if $\left.\frac{\partial(L-F)}{\partial P}\right|_{t_{i}=T_{p}(P)}>$ $(<) 0$.

Proof. From Proposition 2, $\frac{d T_{s}}{d P}=\left(Z^{-1}\right)^{\prime}\left(\pi_{1 L}+P-\pi_{0}\right)<0$.

The leader's preemption investment date is determined by the condition $L\left(T_{p}(P), P\right)=F\left(T_{p}(P), P\right)$ with $L$ cutting $F$ from below. Hence, we know 
that at $T_{p}(P)$ we have $\frac{\partial(L-F)}{\partial t_{i}}>0$. By the Implicit Function Theorem, $\frac{d T_{p}(P)}{d P}=-\frac{\partial(L-F)}{\partial P} / \frac{\partial(L-F)}{\partial t_{i}}$. Therefore the stated result follows.

The result for the preemption equilibrium depends on whether an increase in the access charge benefits or hurts the leader. In order to understand the effects involved, consider

$$
\begin{aligned}
\left.\frac{\partial(L-F)}{\partial P}\right|_{t_{i}=T_{p}(P)} & =\frac{2}{\delta}\left(e^{-\delta T_{p}(P)}-e^{-\delta T_{f}(P)}\right) \\
& +e^{-\delta T_{f}(P)}\left(-\frac{d T_{f}(P)}{d P}\right)\left[\pi_{2 L}-\tilde{\pi}_{1 L}(P)\right] .
\end{aligned}
$$

The first term describes the direct effect on the difference in flow profits during service-based competition. A higher access charge benefits the leader and hurts the follower, thus increasing the incentives for preemption. The second effect, however, an indirect effect caused by the anticipation of the follower's investment, may go both ways. If the leader's profits increase after duplication, i.e. $\pi_{2 L}>\tilde{\pi}_{1 L}(P)$, then earlier duplication again benefits the leader, and higher $P$ indeed makes the leader invest earlier. On the other hand, if after duplication its profits decrease substantially, the total effect may become negative. As a result, the returns from the first investment decrease, and the leader delays investment.

We still need to determine for which values of $P$ we have a waiting or preemption equilibrium. As we have seen, for $P \geq \pi_{1 F}-\pi_{0}$ we definitely have preemption, thus without the provision of access we would always obtain preemption. For $P<\pi_{1 F}-\pi_{0}$ we may have a preemption or waiting equilibrium, depending on whether $T_{p}(P)$ is smaller or larger than $T_{s}(P)$. For our generic functional forms, there may be none, one, or more than one $\hat{P} \in\left(0, \pi_{1 F}-\pi_{0}\right)$ with $T_{p}(\hat{P})=T_{s}(\hat{P})$, which are the values of the access charge for which we have transitions between both types of equilibria. As we will show in the next section, since the leader will only invest at the socially optimal date if the regulator induces a preemption equilibrium, this possible multiplicity of transitions between waiting and preemption equilibria poses no problem.

For completeness, we discuss briefly the possible cases. If there is no transition then we always have preemption. If there is one transition then we have a second-mover advantage when the access charge is low and a firstmover advantage for high $P$, i.e., there is a waiting equilibrium for $P \in$ $[0, \hat{P}]$ and preemption for $P \in\left(\hat{P}, \pi_{1 F}\right]$. The leader's investment date is a 
continuous function of the access charge:

$$
\widetilde{T}_{L}(P)=\left\{\begin{array}{ll}
T_{s}(P) & \text { if } \quad 0 \leq P \leq \hat{P} \\
T_{p}(P) & \text { if } \quad \hat{P}<P \leq \pi_{1 F}
\end{array} .\right.
$$

This function decreases on the first branch, but may be increasing for high $P>\pi_{2 L}-\pi_{1 L}$ on the second branch.

On the other hand, there may be more than one $P$ such that $T_{p}(P)=$ $T_{s}(P)$. The reason is that both the stand-alone and preemption investment dates may decrease in parallel with a higher access charge. In fact, if $P$ increases we have a transition from a waiting to a preemption equilibrium if and only if $T_{p}(P)$ falls below $T_{s}(P)$, i.e. if

$$
\left.\frac{d T_{s}(P)}{d P}\right|_{T_{p}=T_{s}}-\left.\frac{d T_{p}(P)}{d P}\right|_{T_{p}=T_{s}}>0 .
$$

The first term is always negative, pointing towards a transition to waiting, while the second term can be either positive or negative. We can sign the whole expression unambiguously only in the case where a higher access charge delays preemptive investment, which forces a transition to a waiting equilibrium.

\section{Socially Optimal Investment Timing}

Social welfare is defined as the present value of the intertemporal stream of social benefits (profits and consumer surplus) minus discounted investment costs. Let $S_{0}$ be consumer surplus per period when neither firm has invested. $S_{1}$ is consumer surplus per period when one firm has invested in a new infrastructure, and the other has access to it. $S_{2}$ is consumer surplus per period when both firms have invested. Note that $S_{1}$ is independent of $P$ since it is a lump-sum payment from the follower to the leader. We assume that consumer surplus does not decrease after the first investment:

$$
S_{1} \geq S_{0}
$$

Total welfare per period for each of the three cases is:

$$
\begin{aligned}
& w_{0}=2 \pi_{0}+S_{0} \\
& w_{1}=\pi_{1 L}+\pi_{1 F}+S_{1} \\
& w_{2}=\pi_{2 L}+\pi_{2 F}+S_{2} .
\end{aligned}
$$

We assume that total welfare (before investment cost) increases with both investments, and that both eventually are socially desirable, though only 
after date zero. Furthermore, we assume that total welfare increases more with the first investment than with the second one:

$$
Z(0)>w_{1}-w_{0}>w_{2}-w_{1}>\delta \underline{C} .
$$

Note that this assumption does not follow from the previous ones, because it also includes the possible reductions in payoffs by the firm which does not invest.

With investment dates $t_{i} \leq t_{j}$, discounted net social welfare is given by:

$$
\begin{aligned}
W\left(t_{i}, t_{j}\right) & =\left(1-e^{-\delta t_{i}}\right) \frac{w_{0}}{\delta}+\left(e^{-\delta t_{i}}-e^{-\delta t_{j}}\right) \frac{w_{1}}{\delta} \\
& +e^{-\delta t_{j}} \frac{w_{2}}{\delta}-A\left(t_{i}\right)-A\left(t_{j}\right) .
\end{aligned}
$$

The socially optimal investment dates are easily characterized:

Proposition 7 Socially optimal investment occurs at dates $T_{F}^{s o}>T_{L}^{s o}>0$, with

$$
T_{F}^{s o}=Z^{-1}\left(w_{2}-w_{1}\right), \quad T_{L}^{s o}=Z^{-1}\left(w_{1}-w_{0}\right) .
$$

Proof. The regulator maximizes $W$ over $t_{i} \leq t_{j}$, with first order conditions

$$
\begin{aligned}
& w_{1}-w_{0}=Z\left(T_{L}^{s o}\right), \\
& w_{2}-w_{1}=Z\left(T_{F}^{s o}\right) .
\end{aligned}
$$

The left hand sides of both conditions are larger than $\delta \underline{C}$ by assumption (19). Thus $T_{L}^{s o}=Z^{-1}\left(w_{1}-w_{0}\right)$ and $T_{F}^{s o}=Z^{-1}\left(w_{2}-w_{1}\right)$ are well defined and unique. Assumption (19) also guarantees that $T_{L}^{s o}>0$ and $T_{L}^{s o}<T_{F}^{s o}$.

\section{Optimal Regulation}

Having determined the socially optimal investment dates, we now consider how a regulator can induce a socially optimal investment pattern using $e x$ ante regulation.

For a start, we find the access charge such that each firm invests at the corresponding socially optimal date.

Proposition 8 The follower invests at the socially optimal date with the access charge $P_{F}^{*} \equiv S_{2}-S_{1}+\pi_{2 L}-\pi_{1 L}$ if $0 \leq P_{F}^{*} \leq \pi_{1 F}$. 
Proof. Immediate from $T_{f}\left(P_{F}^{*}\right)=T_{F}^{s o}$.

When a follower invests, it changes its payoff but also consumer surplus and the leader's payoff. However, in its decision it does not take the latter into account. Hence, the regulator needs to make it internalize these effects through the access charge.

Proposition 9 Let $P_{L}^{*}$ be a solution of $T_{p}\left(P_{L}^{*}\right)=T_{L}^{s o}$. If $0 \leq P_{L}^{*} \leq \pi_{1 F}$, then the leader invests at the socially optimal date. This access charge results in preemption, while socially optimal investment by the leader cannot be achieved through a waiting equilibrium (with a time-invariant access charge).

Proof. Suppose $P$ is such that we have a waiting equilibrium, which implies $P<\pi_{1 F}-\pi_{0}$. If $T_{L}^{s o} \geq T_{s}(P)$ then by definition of these two dates $P \geq \pi_{1 F}-\pi_{0}+S_{1}-S_{0}$, which contradicts $P<\pi_{1 F}-\pi_{0}$ by (17). Therefore for this $P$ we have $T_{L}^{s o}<T_{s}(P)$. In other words, if there is to be socially optimal investment by the leader it must be in a preemption equilibrium.

The leader always invests too late in waiting equilibria, because it considers only its private gains. As a result, the regulator needs to induce a preemption equilibrium, using an access charge that is high enough, if he wants to achieve socially optimal investment by the leader.

Now let us assume that both $P_{L}^{*}$ and $P_{F}^{*}$ belong to the interval $\left[0, \pi_{1 F}\right]$, similar to Gans (2001), while we leave open which of the two is larger. Contrary to the latter paper, where a two-part tariff achieves socially optimal investment, in our model the regulator generically cannot achieve socially optimal investment by both firms using the access charge. In fact, he only has one instrument and two objectives. Hence, the second-best access charge $P^{s o} \in \arg \max _{P} W\left(T_{p}(P), T_{f}(P)\right)$ is somewhere between $P_{L}^{*}$ and $P_{F}^{*}$, with one firm investing too early and the other too late as compared to the first best.

A further problem is that this second-best access charge lacks time consistency. If the regulator does not commit to this price, and revises it after the leader's investment, he would change it to $P_{F}^{*}$. If the leader foresees this it would invest at $\widetilde{T}_{L}\left(P_{F}^{*}\right)$, and ex-ante welfare would be lower.

Given that in our model access is priced using a two-part tariff, if the regulator only aims for dynamic efficiency and ignores static efficiency, he could try to use the usage charge $a$ as an instrument to induce a first-best investment pattern with a time-consistent access charge $P$. He would have 
to choose $\widetilde{a}$ such that $P_{L}^{*}(\widetilde{a})=P_{F}^{*}(\widetilde{a})$. Unfortunately, there is no simpler or explicit condition describing this level of usage charge, so that it is hard to tell whether such $\widetilde{a}$ even exists.

According to De Bijl and Peitz (2004), with full participation and inelastic demand, static welfare is independent of the usage charge. In this case, the increase in the usage charge is totally passed on to consumers by the follower, while the leader takes all the benefits from this increase. This implies that a regulator has some freedom to set the usage charge for dynamic objectives. However, for new services, we do not have full participation, and thus there will be a usage charge which maximizes static welfare. In this case, a regulator has to sacrifice static welfare if he wants to use the usage charge for dynamic objectives.

The regulator could use instead a time-variant access charge, as in Bourreau and Dogan (2006) or Vareda and Hoernig (2007), an earlier version of this paper. In principle, the path of access charges could define a different value for each moment in time, resulting in an infinite number of instruments. We will not consider this case here because commitment by regulators to such access charge paths is problematic. Regulatory pricing decisions usually are valid for a few years only, after which new prices are set. Furthermore, the regulators' directors are changed at regular intervals, which makes long-term commitment more difficult.

In order to ease problems of commitment, we will discuss some simpler regimes that can be seen as particular cases of time-variant access charges, where the price is changed only once, either from or to infinity (or some other value above $\pi_{1 F}$ ). The first is a banned access regime where the regulator sets a date after which the follower can no longer ask for access to the leader's infrastructure. Note that this banned access regime does not correspond to a "sunset clause". Sunset clauses specify ex ante a period of time after which the leader's network is no longer regulated. In our case, the regulator continues to intervene by banning service-based competition. In fact, if the regulator just withdrew from market intervention the leader might continue to give access to the follower for some time in order to delay its investment, as in Bourreau and Dogan (2006).

The second regime is one of access holidays, where there is no access obligation for a certain period of time right after the leader's investment. The new point in our analysis is to not consider access holidays in isolation, but to link them to lower access prices afterwards. The decision variable in this case is the exact length of these access holidays. Note that during the access holidays the leader, while not being subject to an access obligation, can opt to give access to the follower. However, it has no incentive for doing 
so since, as we will see, it would not be able to delay the follower's investment date and because its profit is higher with monopoly.

In a banned access regime, the regulator, besides setting an access tariff as before, also fixes a date $T_{B A}$ after which access is banned.

Since the leader's stand-alone investment date $T_{s}(P)$ does not change if the follower invests at $T_{F}^{s o}$ instead of $T_{f}(P)$, the same argument as in Proposition 9 applies, and efficient investment can only be achieved in a preemption equilibrium.

Let us define $P_{L}^{* *}$ as the access charge that induces preemption at the socially optimal first investment date when firms know that the second investment will also occur optimally: $\tilde{L}\left(T_{L}^{s o}, T_{F}^{s o}, P_{L}^{* *}\right)=\tilde{F}\left(T_{L}^{s o}, T_{F}^{s o}, P_{L}^{* *}\right)$, or

$$
P_{L}^{* *}=\frac{\delta\left(A\left(T_{L}^{s o}\right)-A\left(T_{F}^{s o}\right)\right)-\left(\pi_{2 L}-\pi_{2 F}\right) e^{-\delta T_{F}^{s o}}}{2\left(e^{-\delta T_{L}^{s o}}-e^{-\delta T_{F}^{s o}}\right)}-\frac{\pi_{1 L}-\pi_{1 F}}{2} .
$$

Thus the difference between $P_{L}^{*}$ and $P_{L}^{* *}$ is that the former supposes that the second investment is at the non-optimal date $T_{f}\left(P_{L}^{*}\right)$. We now consider two cases, depending whether at access price $P_{L}^{* *}$ the follower would invest too late or too early.

Proposition 10 If $0 \leq P_{L}^{* *} \leq P_{F}^{*}$, with $P=P_{L}^{* *}$ and $T_{B A}=T_{F}^{s o}$ both firms invest at their socially optimal dates.

Proof. At time $t \geq T_{L}^{s o}$ the follower solves:

$$
\max _{t_{j} \geq t}\left\{\frac{e^{-\delta t}-e^{-\delta \min \left\{t_{j}, T_{B A}\right\}}}{\delta} \tilde{\pi}_{1 F}\left(P_{L}^{* *}\right)+\frac{e^{-\delta t_{j}}}{\delta} \pi_{2 L}-A\left(t_{j}\right)\right\} .
$$

Taking the first-order condition we obtain:

$$
\begin{aligned}
\pi_{1 F}-\pi_{2 F}-P_{L}^{* *}+Z\left(t_{j}\right) & >0 \text { for } t_{j}<T_{B A} \\
-\pi_{2 F}+Z\left(t_{j}\right) & <0 \text { for } t_{j}>T_{B A}
\end{aligned}
$$

Hence, the follower invests at $T_{B A}=T_{F}^{s o}$, and since $P_{L}^{* *} \leq P_{F}^{*} \leq \pi_{1 F}$ the follower asks for access before $T_{F}^{s o}$.

Since the leader receives $P_{L}^{* *}$ during the whole duration of service-based competition, the first investment will occur at the socially optimal investment date $T_{L}^{s o}$.

Thus if $P_{L}^{* *} \leq P_{F}^{*}$ the follower can be induced to invest at $T_{F}^{s o}$ simply by ending access to the leader's network at the date when investment is meant to 
occur. This regime is time-consistent and corresponds to the recommendation in Cave and Vogelsang (2003) of access pricing that are increasing over time.

Still, if $P_{L}^{* *}>P_{F}^{*}$ then the above regulatory regime does not lead to the first best: the follower will invest too early at $T_{f}\left(P_{L}^{* *}\right)$. This case arises if the follower's payoff increases very strongly after duplication, while total surplus increases little, i.e. the follower's gains are mainly due to business stealing. If the regulator wants the follower to invest at $T_{F}^{s o}$ he needs to set the lower access charge $P_{F}^{*}$. However, an access charge at this level, and for the whole time interval between the first and second investments, will induce the leader to invest later than $T_{L}^{s o}$. In this case, a regime of banned access is useless, since anyway the follower invests earlier than optimal. Therefore, we suggest the adoption of access holidays.

"Access holidays" consists of a fixed time period after the leader's investment during which the leader is not subject to mandatory access, see e.g. Gans and King (2004). In our model the leader would earn the monopoly profit $\pi_{1 M}$ during this period. Since this is higher than $\tilde{\pi}_{1 L}(P)$ for all $P$ at which the follower asks for access, access holidays provide an additional means for the regulator to guarantee rents to the firm making the first investment.

Indeed, when there exists an unresolved conflict between the necessity of high access charges to make the leader invest optimally, and low access charges to keep the follower from investing too early, access holidays can help solve this problem, to some extent, by raising the leader's payoffs right after investment. The core of our argument is that the higher is the length of the access holiday the higher is the regulator's degree of freedom to set a lower access price after ending the "holidays". Therefore, he will at least be able to induce both firms to invest closer to socially optimal. Naturally, since the follower receives zero profits without access, it would like to invest even earlier if the access holiday lasts too long and the leader opts to not give access during that period. This limits the additional rents that can be given to the leader.

Moreover, there is an additional downside: By granting access holidays, the regulator is sacrificing static welfare, and the first-best cannot be achieved even if the restriction we have just mentioned is not binding. Thus these holidays should have the minimum duration needed to yield the necessary increase in rents given that some $P_{H}<P_{L}^{* *}$ is charged afterwards. In fact, paths of access prices that decrease towards $P_{F}^{*}$ and do not make the follower invest immediately yield even higher rents to the leader. These would lead to shorter access holidays and higher welfare, but, as argued above, may be much more difficult for the regulator to commit to ex ante. 
Formalizing the problem, now the leader's investment date depends on both the access charge and the duration of the access holidays. If there still is a period of service-based competition, the access holidays do not influence the follower's investment date $T_{f}(P)$. Hence, defining the duration of the access holidays as $H$, we have:

$$
\begin{aligned}
L\left(t_{i}, P, H\right)-F\left(t_{i}, P, H\right) & =\left(e^{-\delta t_{i}}-e^{-\delta\left(t_{i}+H\right)}\right) \frac{\pi_{M}}{\delta} \\
& +\left(e^{-\delta\left(t_{i}+H\right)}-e^{-\delta T_{f}(P)}\right) \frac{\tilde{\pi}_{1 L}(P)-\tilde{\pi}_{1 F}(P)}{\delta} \\
& +e^{-\delta T_{f}(P)} \frac{\pi_{2 L}-\pi_{2 F}}{\delta}-A\left(t_{i}\right)+A\left(T_{f}(P)\right) .
\end{aligned}
$$

According to this expression, and given that $\pi_{M}>\tilde{\pi}_{1 L}(P)$, preemption occurs earlier the longer is the access holiday period, i.e. $\partial T_{p}(P, H) / \partial H<0$. The leader's stand-alone investment date also depends on the access holiday since its problem is now:

$$
\max _{t_{i}}\left\{\begin{array}{ccc}
\frac{\pi_{M}-\pi_{0}}{\delta} e^{-\delta t_{i}}+\frac{\tilde{\pi}_{1 L}(P)-\pi_{M}}{\delta} e^{-\delta\left(t_{i}+H\right)}+\ldots-A\left(t_{i}\right) & \text { if } & 0 \leq t_{i}<T_{f}(P) \\
\frac{\pi_{2 L}-\pi_{0}}{\delta} e^{-\delta t_{i}}+\ldots-A\left(t_{i}\right) & \text { if } & t_{i} \geq T_{f}(P)
\end{array},\right.
$$

from where we obtain

$$
T_{s}(P, H)=Z^{-1}\left[\tilde{\pi}_{1 L}(P)-\pi_{0}+\left(\pi_{M}-\tilde{\pi}_{1 L}(P)\right)\left(1-e^{-\delta H}\right)\right],
$$

and thus $\partial T_{s}(P, H) / \partial H<0$. We can then conclude that the leader's equilibrium investment date $\widetilde{T}_{L}(P, H)$ is decreasing in the length of the access holiday.

The regulator's problem is:

$$
\begin{aligned}
\max _{H, P}\{ & \left(1-e^{-\delta \widetilde{T}_{L}(H, P)}\right) \frac{w_{0}}{\delta}+\left(e^{-\delta \widetilde{T}_{L}(H, P)}-e^{-\delta\left(\widetilde{T}_{L}(H, P)+H\right)}\right) \frac{w_{M}}{\delta} \\
& +\left(e^{-\delta\left(\widetilde{T}_{L}(H, P)+H\right)}-e^{-\delta \widetilde{T}_{F}(P)}\right) \frac{w_{1}}{\delta}+e^{-\delta \widetilde{T}_{F}(P)} \frac{w_{2}}{\delta} \\
& \left.-A\left(\widetilde{T}_{L}(H, P)\right)-A\left(\widetilde{T}_{F}(P)\right)\right\},
\end{aligned}
$$

subject to the condition that the follower will not invest before $\widetilde{T}_{L}(H, P)+H$. The optimum will involve a trade-off between optimal investment by the leader, given by the terms

$$
e^{-\delta \widetilde{T}_{L}(H, P)} \frac{w_{1}-w_{0}}{\delta}-A\left(\widetilde{T}_{L}(H, P)\right),
$$

and the loss in static welfare

$$
e^{-\delta \widetilde{T}_{L}(H, P)}\left(1-e^{-\delta H}\right) \frac{w_{M}-w_{1}}{\delta} .
$$


Therefore the access holidays will be shorter than needed to make the leader invest optimally in order to limit the loss in static welfare. In order to at least partially make up for this, and since welfare is flat at the follower's first-best investment date, the access prices charged to the follower later on will be somewhat above $P_{F}^{*}$, and the follower will invest too early.

The optimal duration of the access holidays cannot be such that the follower invests before they end, since in this case the follower would be investing too soon and there would be welfare losses resulting from monopoly. Indeed, this solution is dominated by a regime where the regulator sets the access holiday to end right before inducing investment by the follower, and then $P<\pi_{1 F}$, as both the leader and the follower would invest closer to optimal. This, together with higher flow profits during monopoly, implies that the leader will not offer access during the access holidays period.

If the regulator cannot commit to the access charge set in this regime, he will revise it to $P_{F}^{*}<P_{H}$ immediately after the end of the access holidays, in order to induce the follower to invest optimally. However, this will make the leader delay its investment if it foresees this. In this case, when the regulator sets the access holiday period, he must take into account that the access charge will be $P_{F}^{*}$. If he is able to commit to the length of the access holidays, these will have to be longer than with commitment to length and access price. Thus, there clearly is a social cost of not being able to commit.

\section{$7 \quad$ Extensions}

\subsection{Undesirable bypass}

Until now we have assumed that a bypass investment is desirable both for the follower and the regulator, see assumptions (6) and (19). In this section we change both assumptions.

Case 1: Socially desirable but privately undesirable bypass

This situation corresponds to the following assumption:

$$
w_{2}-w_{1}>\delta \underline{C}>\pi_{2 F}-\pi_{1 F}
$$

Here the regulator would like to encourage the follower to invest. This he can only achieve with a sufficiently high access charge:

$$
P>\bar{P}=\delta \underline{C}-\left(\pi_{2 F}-\pi_{1 F}\right) .
$$


Thus, if $\pi_{2 F}>\delta \underline{C}$, for $P>\bar{P}$ the follower duplicates at some $t<+\infty$, and for $P \leq \bar{P}$ the follower does not duplicate. By (27), we have:

$$
P_{F}^{*}=\left(w_{2}-w_{1}\right)-\left(\pi_{2 F}-\pi_{1 F}\right)>\bar{P} .
$$

That is, the regulator cannot only induce the follower to invest at all, but even to invest at the optimal date. Therefore, the regulatory regimes discussed in the previous section can equally be applied.

\section{Case 2: Socially undesirable bypass}

We continue to assume that the first investment is socially desirable, but that the second one is not:

$$
w_{1}-w_{0}>\delta \underline{C} \geq w_{2}-w_{1} .
$$

Again, the stand-alone and optimal investment dates of the leader remain the same. Thus the regulator needs to induce investment in a preemption equilibrium, for example by choosing a constant access charge $P_{L}^{*}$ such that $\tilde{L}\left(T_{L}^{s o}, \infty, P_{L}^{*}\right)=\tilde{F}\left(T_{L}^{s o}, \infty, P_{L}^{*}\right)$. This condition is equivalent to

$$
P_{L}^{*}=\frac{1}{2}\left(\delta A\left(T_{L}^{s o}\right) e^{\delta T_{L}^{s o}}-\pi_{1 L}+\pi_{1 F}\right)
$$

At this access charge the follower will not invest if $\pi_{2 F}-\tilde{\pi}_{1 F}\left(P_{L}^{*}\right) \leq \delta \underline{C}$, i.e. $P_{L}^{*} \leq \delta \underline{C}-\pi_{2 F}+\pi_{1 F}$. If $P_{L}^{*}$ is larger than this value, the regulator must set the access charge at most at this level such as to avoid inducing investment by the follower. Similar to what we discussed above, in this case the regulator can again use access holidays in order to guarantee the rents which make the leader invest at (or at least closer to) the optimal date, while later being able to charge a lower access price.

\subsection{Ex-ante asymmetry}

In this section we extend our model to the case where firms are ex-ante asymmetric. This portrays the situation when there is an incumbent firm owning a network which can be used for providing the new services. This firm just needs to upgrade its existing network to start supplying the services, while its competitor would have to build an entire new network.

This asymmetry is modeled by assuming that one of firms has a lower cost of investing in the new network infrastructure than the other. For simplicity, let the investment cost of one of the firms, say firm $B$, be $C_{B}(t)=C(t)+K$, while the investment cost of firm $A$ is $C(t)$. Investment $K>0$ corresponds 
to the duplication of the necessary parts of the incumbent's network. We assume here

$$
K<\frac{\min \left\{\pi_{2 F}-\pi_{1 F}, w_{2}-w_{1}\right\}}{\delta}-\underline{C},
$$

so that a bypass investment is privately and socially desirable.

According to this formulation, firm $A$ 's stand-alone and preemption investment dates $\left(T_{f}^{A}(P), T_{S}^{A}(P), T_{p}^{A}(P)\right)$ are the same as the ones found in previous sections, but firm $B$ 's investment dates will change.

Proposition 11 Given the access charge $P$, firm B's stand-alone investment dates as a follower and as a leader, $T_{f}^{B}(P), T_{S}^{B}(P)$, and preemption date, $T_{p}^{B}(P)$, occur later than firm $A$ 's, and are all delayed with increases in $K$.

\section{Proof. See Appendix C.}

Since future profit flows of firm $B$ are reduced by the annuity $\delta K$, it has fewer incentives to invest, whatever is the position it assumes in the investment race. Therefore, its investment dates are all delayed in comparison with firm $A$, being this delay higher, the higher is the degree of asymmetry.

In this case, the equilibrium investment timing becomes similar to Riordan (1992):

Proposition 12 For all $P \in\left[0, \pi_{1 F}\right]$, in the unique subgame-perfect equilibrium, firm $B$ is the follower and invests at $\widetilde{T}_{F}(P)=T_{f}^{B}(P)$, while firm $A$ is the leader and invests at $\widetilde{T}_{L}(P)=\min \left\{T_{p}^{B}(P), T_{s}^{A}(P)\right\}$.

Proof. See Theorem 1, part (i) of Riordan (1992).

Again we can have a preemption or a waiting equilibrium, according to which of $T_{p}^{B}(P)$ and $T_{s}^{A}(P)$ occurs earlier. According to Proposition 11, if $K$ is big then $T_{p}^{B}(P)$ occurs very late, and thus even for high $P$ we have $T_{s}^{A}(P)<T_{p}^{B}(P)$. In this case, the leader invests at its stand-alone investment date, but contrary to previous sections it has a first-mover advantage. Therefore we say, according to the terminology of Riordan (1992), that firm $A$ is a strong leader. If $K$ is small, things will be qualitatively similar to the previous sections, but firm $A$ definitely becomes the leader, in the terminology of Riordan (1992), a weak leader. What is different from the symmetric case is that "rent equalization" does not occur: $A$ 's discounted profits as leader at its investment date are strictly higher than what it would earn as a follower if firm $B$ invested at this date. 
The effect of the access tariff on the leader's and follower's investment dates is similar to Propositions 5 and 6 , since dates are defined similarly. Still, for the regulator it is better to have firm $A$ as the leader and firm $B$ as the follower, in order to delay the investment cost of $K$ by firm $B$. This preference is met in equilibrium, therefore the regulator does not need to be concerned with the order of investments, only with the respective investment dates.

Proposition 13 The socially optimal investment timing by the leader can be achieved in a waiting game with the access charge $P_{L}^{w}=S_{1}-S_{0}+\pi_{1 F}-\pi_{0}$ if $T_{p}^{B}\left(P_{L}^{w}\right) \geq T_{s}^{A}\left(P_{L}^{w}\right)$ and $0 \leq P_{L}^{w} \leq \pi_{1 F}$. If $T_{p}^{B}\left(P_{L}^{w}\right)<T_{s}^{A}\left(P_{L}^{w}\right)$ then the regulator can achieve optimal investment only in a preemption game (at least with a fixed access price).

Proof. Immediately from Proposition 12 and $T_{s}^{A}\left(P_{L}^{w}\right)=T_{L}^{s o}$.

With asymmetry between firms, it is possible to make the leader invest at the socially optimal date in a waiting equilibrium when $K$ is high enough, since in this case, and contrary to the previous sections, firm $A$ invests at its stand-alone investment date also for high $P$. Indeed, when firm $A$ is a strong leader, the regulator just needs to make it internalize the effects of its investment on consumer surplus and follower's payoff to induce it to invest at the first best. If firm $A$ is a weak leader, then the regulator needs to induce a preemption equilibrium to achieve socially optimal investment. In both cases the regulator's options are similar to the symmetric case. In particular, banning access or granting access holidays will have the same functions as discussed above.

\section{Conclusions}

This paper demonstrates how mandatory access influences the investment dates of two firms that want to build new infrastructures. As known from the literature on technology adoption, there are two types of equilibria. In the first type there is a first-mover advantage and firms preempt each other. In the second type there is a second-mover advantage, leading to a waiting equilibrium. We show that in the context of access pricing, low access charges may lead to waiting, while high access charges lead to preemption.

While higher access charges make the follower invest earlier, and also the leader in a waiting equilibrium, its effects are ambiguous under preemption. If the stand-alone incentives for investment are strong enough then also under 
preemption the leader's investment will occur earlier. If on the other hand the reduction in payoffs caused by the anticipation of the follower's investment is the determinant factor, then the leader's investment will be delayed by a higher access charge.

Since the regulator needs to induce two firms to invest optimally, the first best cannot be achieved with a fixed two-part access tariff. We show that banning access after some date may lead to first-best investment if the follower's private incentives for investment are small. On the other hand, if the follower's private incentives are dominated by business-stealing, it would invest too early, and banning access after a period of service-based competition is counterproductive. The introduction of access holidays after the leader's investment can alleviate this problem, apart from their more usual role of encouraging the leader's investment.

In case of a large ex-ante asymmetry between firms, socially optimal investment timing can be achieved in a waiting equilibrium. Yet, if the asymmetry is small enough then the regulator needs to encourage preemption, just as in the symmetric case. Finally, no essentially new problems arise if bypass needs to be elicited by the regulator, or if no bypass investment occurs at all.

\section{Appendix A - Proof of Proposition 2}

Given the investment decision of the follower, the leader solves

$\max _{t_{i}}\left\{\begin{array}{ccc}\frac{\tilde{\pi}_{1 L}(P)-\pi_{0}}{\delta} e^{-\delta t_{i}}-A\left(t_{i}\right)+\left[\frac{\pi_{0}}{\delta}+\frac{\pi_{2 L}-\tilde{\pi}_{1 L}(P)}{\delta} e^{-\delta T_{f}(P)}\right] & \text { if } & 0 \leq t_{i}<T_{f}(P) \\ \frac{\pi_{2 L}-\pi_{0}}{\delta} e^{-\delta t_{i}}-A\left(t_{i}\right)+\frac{\pi_{0}}{\delta} & \text { if } & t_{i} \geq T_{f}(P)\end{array}\right.$

Profits are continuous at $t_{i}=T_{f}(P)$. On the branch $t_{i}<T_{f}(P)$, the firstorder condition for an interior maximum is $Z\left(t_{i}\right)=\tilde{\pi}_{1 L}(P)-\pi_{0}$. By assumptions (3) and (6), the following inequalities hold:

$$
\begin{aligned}
& P \leq \pi_{1 F}: \quad \pi_{1 L}+P-\pi_{0}>\pi_{2 F}-\left(\pi_{1 F}-P\right) \\
& P>\pi_{1 F}: \quad \pi_{1 M}-\pi_{0} \geq \pi_{1 L}+\pi_{1 F}-\pi_{0}>\pi_{2 F} .
\end{aligned}
$$

Thus $\tilde{\pi}_{1 L}(P)-\pi_{0}>\pi_{2 F}-\tilde{\pi}_{1 F}(P)$ and $T_{s}(P)=Z^{-1}\left(\tilde{\pi}_{1 L}(P)-\pi_{0}\right)<$ $T_{f}(P)$. Furthermore $T_{s}(P)>0$ because by assumption $(7)$ we have $\tilde{\pi}_{1 L}(P)-$ $\pi_{0}<\pi_{1 M}<Z(0)$. Therefore, on the first branch there is a unique interior maximum at $T_{s}(P)$, and profits on the first branch are decreasing at $t_{i}=$ $T_{f}(P)$.

As concerns the second branch, the first-order condition for an interior maximum is $Z\left(t_{i}\right)=\pi_{2 L}-\pi_{0}$, with solution $T_{s^{\prime}}=Z^{-1}\left(\pi_{2 L}-\pi_{0}\right)$. If $\pi_{2 L}-$ 
$\pi_{0} \geq \pi_{2 F}-\tilde{\pi}_{1 F}(P)$, or $P \leq \pi_{1 F}-\pi_{0}+\pi_{2 L}-\pi_{2 F}$, then $T_{s^{\prime}} \leq T_{f}(P)$, and the maximum on the second branch is at $T_{f}(P)$, where it is dominated by $T_{s}(P)$. If, on the other hand, $P>\pi_{1 F}-\pi_{0}+\pi_{2 L}-\pi_{2 F}$ then $T_{s^{\prime}}>T_{f}(P)$, and we cannot decide whether the global maximum is at $T_{s}(P)$ or $T_{s^{\prime}}$.

\section{Appendix B - Proof of Proposition 3}

We have

$$
\begin{aligned}
L\left(t_{i}, P\right)-F\left(t_{i}, P\right) & =\left(e^{-\delta t_{i}}-e^{-\delta T_{F}\left(t_{i}, P\right)}\right) \frac{\tilde{\pi}_{1 L}(P)-\tilde{\pi}_{1 F}(P)}{\delta} \\
& +e^{-\delta T_{F}\left(t_{i}, P\right)} \frac{\pi_{2 L}-\pi_{2 F}}{\delta}-A\left(t_{i}\right)+A\left(T_{F}\left(t_{i}, P\right)\right),
\end{aligned}
$$

which is continuous by continuity of $L\left(t_{i}, P\right)$ and $F\left(t_{i}, P\right)$. Since $T_{F}\left(T_{f}(P), P\right)=$ $T_{f}(P)$,

$$
L\left(T_{f}(P), P\right)-F\left(T_{f}(P), P\right)=e^{-\delta T_{f}(P)} \frac{\pi_{2 L}-\pi_{2 F}}{\delta} \geq 0,
$$

by assumption (4). We also find that $L(0, P)<F(0, P) \forall P \in\left[0, \pi_{1 F}\right]$ since $F(0, P) \geq 0$ and by assumption $(7) L(0, P)<0$. Thus there is a $T_{p}(P) \in\left(0, T_{f}(P)\right]$ such that $L\left(T_{p}(P), P\right)=F\left(T_{p}(P), P\right)$. We will now show that there is at most one such date with $L\left(t_{i}, P\right)<F\left(t_{i}, P\right)$ for all $t_{i} \in\left[0, T_{p}(P)\right)$, and $L\left(t_{i}, P\right)>F\left(t_{i}, P\right)$ for all $t_{i} \in\left(T_{p}(P), T_{f}(P)\right)$.

Maximizing or minimizing $L-F$ with respect to $t_{i}$ in the interval $\left[0, T_{f}(P)\right]$, we obtain the first-order condition

$$
\frac{\partial(L-F)}{\partial t_{i}}=e^{-\delta t_{i}}\left(\tilde{\pi}_{1 F}(P)-\tilde{\pi}_{1 L}(P)\right)-A^{\prime}\left(t_{i}\right)=0 .
$$

Whenever it holds,

$$
\begin{aligned}
\frac{\partial^{2}(L-F)}{\partial t_{i}^{2}} & =-\delta e^{-\delta T_{i}}\left(\tilde{\pi}_{1 F}(P)-\tilde{\pi}_{1 L}(P)\right)-A^{\prime \prime}\left(t_{i}\right) \\
& =-\delta A^{\prime}\left(t_{i}\right)-A^{\prime \prime}\left(t_{i}\right) \\
& =Z^{\prime}\left(t_{i}\right) e^{-\delta t_{i}}<0
\end{aligned}
$$

so that $(L-F)$ is strictly quasi-concave on $\left[0, T_{f}(P)\right]$. This implies that $L-$ $F$ cuts the horizontal axis from below exactly once, and that any additional cut from above occurs only at $T_{f}(P)$ and if $\pi_{2 L}=\pi_{2 F}$ (In this case we have $L=F$ also at $T_{f}(P)$, but this does not upset the statement).

\section{Appendix C - Proof of Proposition 11}


Given the leader's investment date $t_{i} \geq 0$, if firm $B$ is the follower it solves the following maximization problem

$$
\max _{t_{j} \geq t_{i}}\left\{\frac{\pi_{2 F}-\tilde{\pi}_{1 F}(P)-\delta K}{\delta} e^{-\delta t_{j}}-A\left(t_{j}\right)\right\},
$$

and therefore, following the proof of Proposition 1, its investment date becomes:

$$
T_{F}^{B}\left(t_{i}, P\right)=\max \left\{T_{f}^{B}(P), t_{i}\right\},
$$

with $T_{f}^{B}(P)=Z^{-1}\left(\pi_{2 F}-\tilde{\pi}_{1 F}(P)-\delta K\right)>0$.

Firm $B$ 's stand-alone investment date as a leader results from solving

$$
\max _{t_{i}}\left\{\begin{array}{ccc}
\frac{\tilde{\pi}_{1 L}(P)-\pi_{0}-\delta K}{\delta} e^{-\delta t_{i}}+\ldots-A\left(t_{i}\right) & \text { if } & 0 \leq t_{i}<T_{f}^{A}(P) \\
\frac{\pi_{2 L}-\pi_{0}-\delta K}{\delta} e^{-\delta t_{i}}+\ldots-A\left(t_{i}\right) & \text { if } & t_{i} \geq T_{f}^{A}(P)
\end{array},\right.
$$

which, following the proof of Proposition 2, gives:

$$
\begin{aligned}
T_{s}^{B}(P) & =Z^{-1}\left(\tilde{\pi}_{1 L}(P)-\pi_{0}-\delta K\right) \\
T_{s^{\prime}}^{B} & =Z^{-1}\left(\pi_{2 L}-\pi_{0}-\delta K\right) .
\end{aligned}
$$

From these it is easy to see that:

$$
\frac{\partial T_{f}^{B}(P)}{\partial K}>0, \frac{\partial T_{S}^{B}(P)}{\partial K}>0 .
$$

Therefore, as firm $A$ 's investment dates are obtained with $K=0, T_{f}^{A}(P)<$ $T_{f}^{B}(P)$ and $T_{S}^{A}(P)<T_{S}^{B}(P)$.

Finally, we show that $B$ 's preemption date occurs later than for firm $A$. If at $T_{p}^{A}(P)$ firm $A$ is indifferent between being a leader or a follower, then firm $B$ is better off being a follower:

$$
L_{B}\left(T_{p}^{A}(P), P\right)-F_{B}\left(T_{p}^{A}(P), P\right)=-K\left(e^{-\delta T_{p}^{A}(P)}-e^{-\delta T_{F}^{B}\left(T_{p}^{A}(P), P\right)}\right)<0,
$$

since $T_{p}^{A}(P) \leq T_{f}^{A}(P)<T_{f}^{B}(P) \leq T_{F}^{B}\left(T_{p}^{A}, P\right)$. Hence, following the proof of Proposition 3, its preemption date must occur after $T_{p}^{A}(P)$.

\section{References}

Bourreau, M. and Dogan, P., 2005, "Unbundling the Local Loop", European Economic Review, 49, 173-199.

Bourreau, M. and Dogan, P., 2006, "Build or Buy Strategies in the Local Loop", American Economic Review, 96, 2, 72-76. 
Cave, M. and Vogelsang, I., 2003, "How access pricing and entry interact", Telecommunications Policy, 27, 717-727.

De Bijl, P. and Peitz, M., 2004, "Unbundling the Local Loop: One Way Access and Imperfect Competition", in: R. Dewenter and J. Haucap (eds), Access Pricing: Theory and Practice, Elsevier Science.

FudenberG, D., and Tirole, J., 1985, "Preemption and Rent Equalization in the Adoption of a New Technology", Review of Economic Studies, LII, 383-401.

GAns, J., 2001, "Regulating Private Infrastructure Investment: Optimal Pricing for Access to Essential Facilities", Journal of Regulatory Economics, 20, 2, 167-189.

GAns, J., and KInG, S., 2004, "Access Holidays and the Timing of Infrastructure Investment", Economic Record, 80, 89-100.

Guthrie, G., 2006, "Regulating Infrastructure: The Impact on Risk and Investment", Journal of Economic Literature, 44, 925-972.

Hoppe, H.C., and Lehmann-Grube, U., 2005, "Innovation Timing Games: a general framework with applications", Journal of Economic Theory, 121, $30-50$.

Hori, K. and Mizuno, K., 2006, "Access Pricing and Investment with Stochastically Growing Demand", International Journal of Industrial Organization, 24, 795-808.

Katz, M.L., and Shapiro, C., 1987, "R\&D Rivalry with Licensing or Imitation", American Economic Review, 77, 3, 402-420.

Riordan, M., 1992, "Regulation and Preemptive Technology Adoption", The Rand Journal of Economics, 23, 3, 334-349.

VAlletti, T., 2003, "The theory of access pricing and its linkage with investment incentives", Telecommunications Policy, 27, 659-675.

VAREDA, J., and HoERnig, S., 2007, "The race for telecoms infrastructure investment with bypass: Can access regulation achieve the first best?", CEPR Discussion Paper 6012.

Woroch, G., 2004, "Open Access Rules and Equilibrium Broadband Deployment", mimeo. 